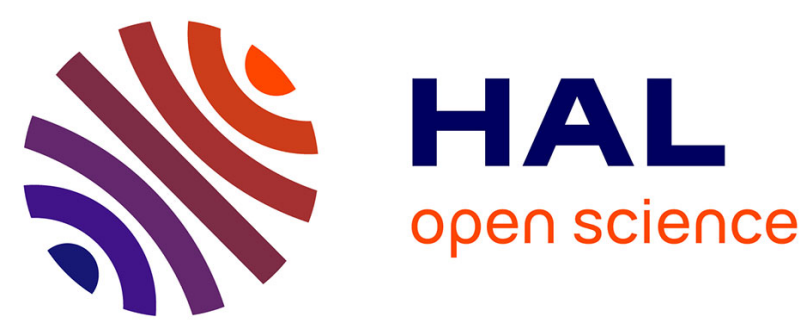

\title{
Psychiatric and cognitive phenotype in children and adolescents with myotonic dystrophy
}

Marie Douniol, Aurélia Jacquette, Jean-Marc Guilé, Marie-Laure Tanguy, Nathalie Angeard, Delphine Héron, Monique Plaza, David Cohen

\section{To cite this version:}

Marie Douniol, Aurélia Jacquette, Jean-Marc Guilé, Marie-Laure Tanguy, Nathalie Angeard, et al.. Psychiatric and cognitive phenotype in children and adolescents with myotonic dystrophy. European Child and Adolescent Psychiatry, 2009, 18 (12), pp.705-715. 10.1007/s00787-009-0037-4 . hal00535161

\section{HAL Id: hal-00535161 \\ https://hal.science/hal-00535161}

Submitted on 11 Nov 2010

HAL is a multi-disciplinary open access archive for the deposit and dissemination of scientific research documents, whether they are published or not. The documents may come from teaching and research institutions in France or abroad, or from public or private research centers.
L'archive ouverte pluridisciplinaire HAL, est destinée au dépôt et à la diffusion de documents scientifiques de niveau recherche, publiés ou non, émanant des établissements d'enseignement et de recherche français ou étrangers, des laboratoires publics ou privés. 


\title{
Psychiatric and cognitive phenotype in children and adolescents with myotonic dystrophy
}

\author{
Marie Douniol · Aurélia Jacquette · Jean-Marc Guilé • \\ Marie-Laure Tanguy $\cdot$ Nathalie Angeard . \\ Delphine Héron · Monique Plaza · David Cohen
}

Received: 21 October 2008/ Accepted: 26 May 2009/Published online: 19 June 2009

(C) Springer-Verlag 2009

\begin{abstract}
Myotonic dystrophy type 1 (DM1) is the most frequent inherited neuromuscular disorder. The juvenile form has been associated with cognitive and psychiatric dysfunction, but the phenotype remains unclear. We reviewed the literature to examine the psychiatric phenotype of juvenile DM1 and performed an admixture analysis of the IQ distribution of our own patients, as we hypothesised a bimodal distribution. Two-thirds of the patients had at least one DSM-IV diagnosis, mainly attention
\end{abstract}

M. Douniol $\cdot$ M. Plaza $\cdot$ D. Cohen $(\bowtie)$

Département de Psychiatrie de l'Enfant et de l'Adolescent,

Université Pierre et Marie Curie, AP-HP,

Hôpital Pitié-Salpêtrière, 47-83, Boulevard de l'Hôpital,

75651 Paris Cedex 13, France

e-mail: david.cohen@psl.aphp.fr

M. Douniol

e-mail: marie.douniol@psl.aphp.fr

M. Douniol · J.-M. Guilé · M. Plaza · D. Cohen

Laboratoire de Psychologie et Neurosciences Cognitives (UMR

CNRS 8189), Institut de Psychologie, Université Paris Descartes,

71 Avenue Edouard Vaillant, 92774 Boulogne

Billancourt Cedex, France

A. Jacquette $\cdot$ N. Angeard · D. Héron

Institut de Myologie et Département de Génétique,

Groupe-Hospitalier Pitié-Salpêtrière AP-HP, 47-83,

Boulevard de l'Hôpital, 75651 Paris Cedex 13, France

J.-M. Guilé

Centre de recherche Fernand Seguin, Université de Montréal,

Hôpital Rivière-des-Prairies, 7070, Boulevard Perras,

Montréal, QC H1E 1A4, Canada

M.-L. Tanguy

Département de Biostatistiques, Groupe-Hospitalier

Pitié-Salpêtrière AP-HP, 47-83, Boulevard de l'Hôpital,

75651 Paris Cedex 13, France deficit/hyperactivity disorder and anxiety disorder. Twothirds had learning disabilities comorbid with mental retardation on one hand, but also attention deficit, low cognitive speed and visual spatial impairment on the other. IQ showed a bi-modal distribution and was associated with parental transmission. The psychiatric phenotype in juvenile DM1 is complex. We distinguished two different phenotypic subtypes: one group characterised by mental retardation, severe developmental delay and maternal transmission; and another group characterised by borderline full scale IQ, subnormal development and paternal transmission.

Keywords Myotonic dystrophy type 1 - Juvenile form · Psychiatric phenotype $\cdot$ Cognitive profile

\section{Introduction}

Myotonic dystrophy 1 (DM1), also called Steinert disease, dystrophic myotonia or myotonic muscular dystrophy, is a progressive neuromuscular disease caused by a genetic mutation and characterised by a wide variation in neuromuscular symptoms and multisystem involvement. DM1 is the most frequently inherited neuromuscular disease, with autosomal dominant transmission. The incidence rate estimate is $1 / 8,000$ [1], although the actual rate is probably higher due to the poor recognition of minor or atypical forms of the disease. Darin et al. [2] estimated the point prevalence in the population under 16 years to be about 5 per 100,000. DM1 is caused by an expanded and unstable CTG repeat sequence in the $3^{\prime}$ untranslated region of the DMPK gene located on the long-arm of chromosome 19. The gene's sequence belongs to the protein kinase family [3-5]. The CTG repeat ranges from 
5 to 37 in the general population, while in DM1 it exceeds 50 and can increase to several thousand units. Progressive expansion of CTG amplification appears both meiotically and mitotically unstable, and is biased toward amplification. This explains both the anticipation phenomenon observed in DM1 pedigrees and the variable clinical expression amongst affected individuals [6]. Type 2 myotonic dystrophy is caused by the mutation of a different gene (ZNF9) and tends to be much milder than DM1.

Myotonic dystrophy type 1 in adults is characterised by myotonia and muscular weakness, but other symptoms can be present depending on the affected organ system. These symptoms include cataracts, smooth muscle disturbances (oesophageal spasms, spastic colon, diarrhoea), gonadal dysfunction in males (subfertility), mental retardation, depression, somnolence, diabetes and cardiac conduction defects (bradycardia, arrhythmias) [7]. Initially considered a peripheral neurological disease, the involvement of the central nervous system in DM1 is now well established. The course of DM1 is marked by hypersomnia, loss of initiative, apathy and cognitive dysfunction (visual spatial and memory deficits) that increase with age. Considering its clinical manifestations and the age of onset, Harley et al. [6] proposed four types of DM: (1) a mild form with cataracts and no or minimal muscular symptoms in middle or older age; (2) a classical form with typical neuromuscular symptomatology in adolescence or early adult life; (3) a juvenile form with learning disabilities often prominent in early life (before the age of 10 years), but with mild, or sometimes even absent, neuromuscular signs at first diagnosis; (4) a congenital form with clinical symptoms present at birth or in utero: hypotonic cerebral palsy, facial diplegia, respiratory and feeding problems and mild to moderate mental retardation in survivors. The congenital form is usually caused by maternal transmission, although a few exceptions have been reported [8].

There have been numerous reports on the somatic signs associated with juvenile DM1, which include difficulties in mastication, deglutition and elocution, smooth muscle disturbances, cardiac conduction defects (bradycardia, arrhythmias), hypofertility and diabetes [9]. However, to date, only a limited number of studies have been conducted on the clinical psychiatric phenotype of juvenile DM1.

The aim of the current report is to clarify the phenotype of the juvenile form of DM 1 by (1) reviewing the literature on the psychiatric phenotype, (2) evaluating more precisely the association between IQ and DM1 by performing an admixture analysis of IQ distribution in our own patients, as we hypothesised a bimodal distribution related to the transmitting parent [10], (3) summarising two paradigmatic clinical vignettes focusing on differential diagnosis.

\section{Methods}

First to review the scientific literature regarding psychiatric and cognitive disorders in juvenile myotonic dystrophy, a systematic search of the MEDLINE database over the period of January 1960 to September 2008 was conducted with the following keywords: myotonic dystrophy or Steinert disease and childhood, yielding 70 articles. Figure 1 summarises the literature search. We screened the abstracts and selected those articles focusing on the cognitive and psychiatric aspects of the juvenile form of DM1. Most of the papers focused on the somatic aspects of the disease $(N=39)$, did not distinguish congenital from juvenile DM1 $(N=3)$, or were not relevant $(N=9)$, and were therefore excluded. We reviewed the reference lists of the selected papers to improve the literature search and found four additional articles. Three articles had no English abstract and were excluded. Finally, we collected 19 articles: 12 case reports [11-21], one study focusing on vigilance and sleep disorders and six studies on the cognitive and psychiatric phenotype of DM1 (Table 1) [22-27].

Second, we hypothesised a bimodal distribution of phenotype related to the transmitting parent. This a priori hypothesis was based on the several facts. (1) In a previous study, we performed on reading and spelling impairments in patients with juvenile DM1 [10], we showed that reading and spelling impairments also occurred in subjects with normal IQ and were correlated with parental transmission. (2) In genetic diseases, parental transmission and imprinting effects are often associated with a bimodal distribution of phenotypes. The more obvious example in child psychiatry is the proximal duplication of chromosome $15 \mathrm{q}$ that is associated with autism when the duplicated material is transmitted by the mother [28]. (3) The bimodal distribution of IQ in Tuberous Sclerosis, another genetic disease with a large phenotype, has been recently evidenced by Winterkorn et al. [29].

Admixture analysis allows testing the assumption that the sample (or observed distribution of the variable) contains several subpopulations by modelling a mixture of distinct multivariate normal distributions. We can identify the number of subpopulations that best fit the observed data and estimate for each of them the characteristics of the distribution (mean and standard error). For example, using this method in samples of bipolar patients, it has been shown that there may be distinct age at onset subgroups amongst bipolar patients [30], and that within 
Fig. 1 Diagram flow of the literature search

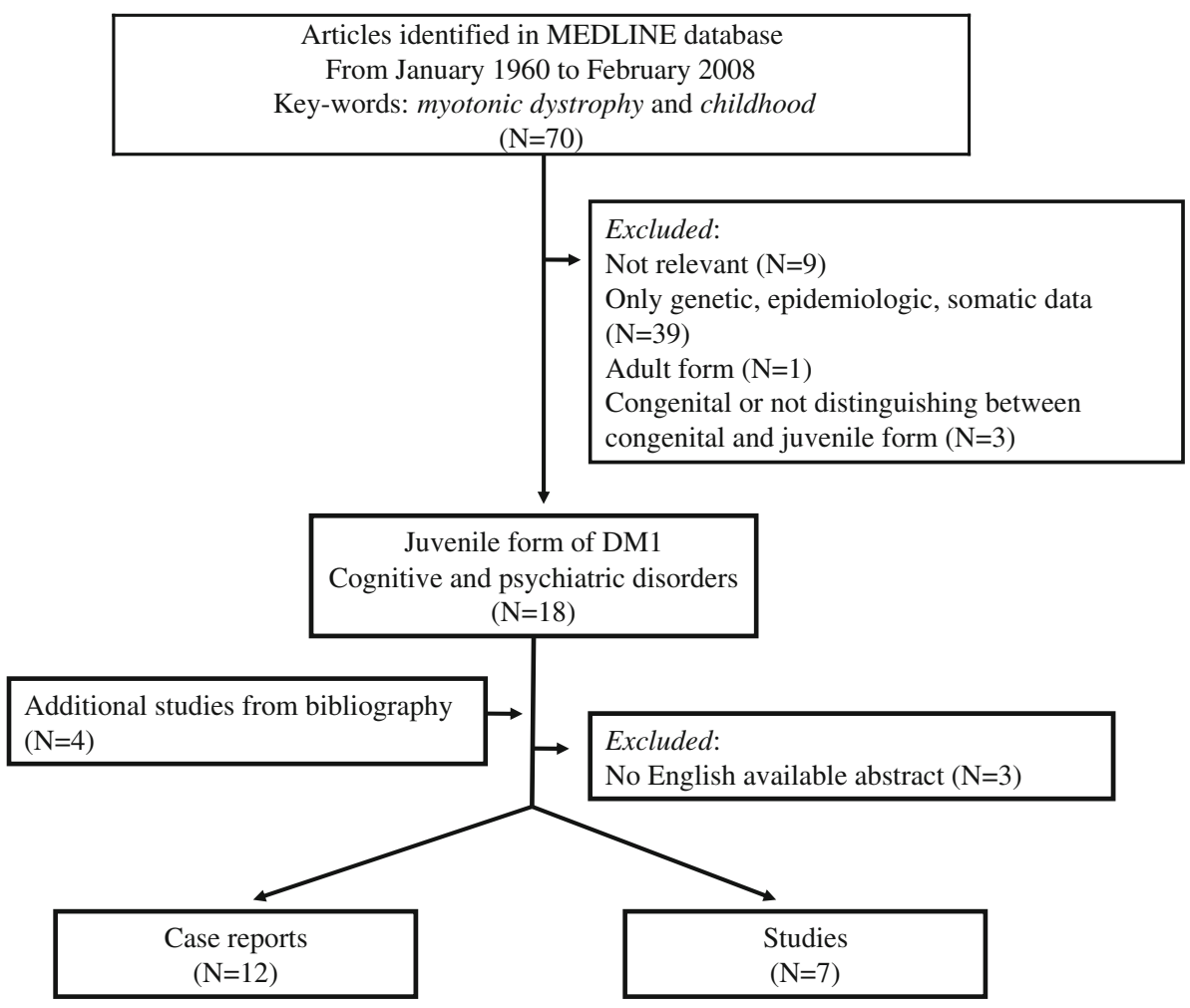

Table 1 Design and main methodological characteristics of the selected studies

\begin{tabular}{|c|c|c|c|c|c|c|}
\hline References & $N$ (age) & $\%$ Male & Mat/pat & Inclusion criteria & Cognitive instruments & $\begin{array}{l}\text { Psychiatric } \\
\text { instruments }\end{array}$ \\
\hline Steyaert et al. [22] & $14(7-18)$ & 44 & $10 / 4$ & $\begin{array}{l}\text { Congenital/juvenile DM1, clinical } \\
\text { setting }\end{array}$ & $\begin{array}{l}\text { WISC-R } \\
\text { WAIS }\end{array}$ & $\begin{array}{l}\text { CBCL } \\
\text { ADIKA }\end{array}$ \\
\hline Goosens et al. [23] & $24(9-22)$ & 58 & $13 / 11$ & $\begin{array}{l}\text { Juvenile DM1, failure at primary } \\
\text { school, clinical setting }\end{array}$ & $\begin{array}{l}\text { WISC-R } \\
\text { WAIS }\end{array}$ & $\begin{array}{l}\text { CBCL } \\
\text { ADIKA }\end{array}$ \\
\hline Quera-Salva et al. [26] & $21(16 \pm 3)$ & 57 & $?$ & $\begin{array}{l}\text { Juvenile DM1, sleep or vigilance } \\
\text { comorbidity, clinical setting }\end{array}$ & & $\begin{array}{l}\text { Sleep questionnaire } \\
\text { Night-time } \\
\text { polysomnography }\end{array}$ \\
\hline Cohen et al. $[10]^{\mathrm{a}}$ & $23(8-18)$ & 61 & $12 / 11$ & Subgroup of Angeard et al. & $\begin{array}{l}\text { WISC-III } \\
\text { Phonology } \\
\text { Word identification } \\
\text { Global reading } \\
\text { Spelling }\end{array}$ & $\begin{array}{l}\text { Learning disability } \\
\text { questionnaire }\end{array}$ \\
\hline Angeard et al. [24] & $36(6-18)$ & 55 & $21 / 15$ & $\begin{array}{l}\text { Juvenile DM1, paternal-maternal } \\
\text { transmission, clinical setting }\end{array}$ & WISC-III & \\
\hline Echenne et al. [25] & $15(8-23)$ & $?$ & $?$ & $\begin{array}{l}\text { Congenital/juvenile DM1, clinical } \\
\text { setting, long-term follow-up }\end{array}$ & WISC-R & $\begin{array}{l}\text { Clinical description } \\
\text { without systematic } \\
\text { instruments }\end{array}$ \\
\hline Ekström et al. [27] ${ }^{\mathrm{a}}$ & $18(8-21)$ & 44 & $13 / 5$ & $\begin{array}{l}\text { Congenital/juvenile DM1, } \\
\text { clinical setting }\end{array}$ & $\begin{array}{l}\text { WISC-III } \\
\text { WAIS III }\end{array}$ & $\begin{array}{l}\text { ADI-R } \\
\text { SCQ } \\
\text { FTF }\end{array}$ \\
\hline
\end{tabular}

$D M 1$ dystrophic myotony $1, C B C L$ child behaviour check list, WISC-R Wechsler intelligence scale-revised, WAIS Wechsler adult intelligence scale, ADI-R Autism diagnostic interview, FTF "Five to Fifteen" parental questionnaire, ADIKA Amsterdam diagnostisch interview voor Kinderen, $S C Q$ social communication questionnaire, ? not reported

${ }^{a}$ The study included 57 subjects, but only 18 with the juvenile form 
bipolar disorder associated with Cotard syndrome, early versus late onset should be distinguished [31]. Therefore, to assess our hypothesis, we collected IQ scores from the study of Angeard et al. as this sample was characterised by an equivalent number of patients with maternal and paternal transmission (see details below), and we performed an admixture analysis to determine the best fitting model for IQ scores in juvenile DM1. Finally, we reported two cases evaluated in our specialised clinics illustrating different aspects of the disease and possible psychiatric differential diagnosis.

\section{Results}

General comments

Despite the frequency of the disease and the prevalence of learning disabilities, we found very limited data related to psychiatric phenotype of DM1: 12 case reports and 7 studies. The classification of Harley et al. [6] was relatively recent (1993), and some articles identified using the literature search could not be exploited as they failed to differentiate between the juvenile and congenital forms of DM1. The remaining case reports were all published more than 10 years ago and represented the assessment of 31 children and adolescents. The seven studies [10, 22-27] were conducted by five groups-Steyaert and Goosens in Belgium; Héron and Eymard, Echenne and Quera Salva in different French settings; and Ekström in Sweden-and included 114 children and adolescents. In total, the current review summarises the data for 145 children and adolescents.

Before summarising the study results, methodological issues should be considered. The design and methodo- logical characteristics of each study are presented in Table 1. As shown in the table, no study was exhaustive. Most studies evaluated general cognitive abilities, but only two had a systematic assessment of axis 1 psychiatric disorders (Steyaert, Goosens). One study focused on reading and spelling impairments (Cohen), one focused on autistic symptoms (Ekström) and one evaluated sleep and vigilance impairments using polysomnography (Quera Salva). Studies were also heterogeneous with respect to inclusion criteria, with a tendency for recruiting patients with maternal transmission-that is to say, more severe phenotypes. Finally, only one study included data on the symptomatic course and outcome of the disease (Echenne).

Based on this review, on both previous single case descriptions and on our own experience (Cases 1 and 2), we propose to classify the psychiatric phenotype into three symptom groups: (1) general cognitive functioning, (2) developmental delay and learning disabilities, (3) psychiatric symptoms.

\section{General cognitive functioning}

The individual full scale IQ varied across the studies from 42 to 114 , but the mean IQ was globally similar, 69.75-80, which is in the borderline range (Table 2). Twenty-three patients amongst the 31 single case reports had mental retardation $[11,14-17,19,20]$. Analysis of the Wechsler subscales showed no difference between the average performance IQ (PIQ) and the average verbal IQ (VIQ) in the studies of Steyaert et al. [22] and Goosens [23], but in the largest study [24], a significant difference was found between VIQ and PIQ (Table 2): a 10-point discrepancy, required for establishing clinical difference at the 0.05 level, was found in 16 of 36 subjects (44\%), with no difference between the two inheritance groups. These results

Table 2 General cognitive functioning in juvenile DM1

\begin{tabular}{|c|c|c|c|c|c|}
\hline & $\begin{array}{l}\text { Steyaert } \\
(N=16)\end{array}$ & $\begin{array}{l}\text { Goosens } \\
(N=24)\end{array}$ & $\begin{array}{l}\text { Angeard } \\
(N=36)\end{array}$ & $\begin{array}{l}\text { Echenne } \\
(N=15)\end{array}$ & $\begin{array}{l}\text { Ekstrom } \\
(N=18)\end{array}$ \\
\hline Full IQ range & $62-95$ & $50-97$ & $42-114$ & $47-85$ & $<70: 89 \%^{\mathrm{a}}$ \\
\hline Full IQ mean (SD) & 80 & $72.25(14)$ & $69.75(19.1)$ & Median: 61 & \\
\hline Performance IQ mean (SD) & 82 & & $68.7(15.8)$ & Median: 60.5 & \\
\hline Verbal IQ mean (SD) & 79 & & $76.4(20.9)$ & Median 68.5 & \\
\hline Dissociation VIQ/PIQ & NS & NS & $P<0.0001$ & & \\
\hline \multicolumn{6}{|l|}{ Genotype/phenotype correlates } \\
\hline Correlation CTG repeat/full IQ score & + & & $P<0.05$ & + & $P<0.0001$ \\
\hline Maternal/paternal transmission & $N=10 / 4$ & $N=13 / 11$ & $N=21 / 15$ & & $N=13 / 5$ \\
\hline Association parental inheritance mode/full IQ score & & $P=0.034$ & $P=0.001$ & & $P<0.001$ \\
\hline
\end{tabular}

$D M 1$ dystrophic myotony $1, I Q$ intellectual quotient, VIQ verbal IQ, PIQ performance IQ

${ }^{\mathrm{a}} \mathrm{IQ}<50$ : 50\%; $50<\mathrm{IQ}<70$ : $39 \%$; $70<\mathrm{IQ}<85$ : 5.5\%; IQ > 85: $85 \%$ 
were confirmed in Cohen's study [10], with a significant difference between VIQ and PIQ in subjects without mental retardation.

The analysis of the effect of the CTG repeat number led to the same results in all studies. The expansion lengths correlated with the transmitting parent's sex; inheritance from the mother gave a longer expansion length than that from the father. In addition, a significant effect of the transmitting parent's sex on the IQ scores of the affected child was found [10, 22-24, 27]. Moreover, significant correlations between IQ scores and the CTG repeat number were established [24, 27].

Some case reports showed that some individuals exhibited cognitive decline over time [11, 20, 22]. Echenne et al. [25] assessed this issue by repeated IQ evaluation of eight patients with juvenile DM1. Three children showed stable results over time, and five showed a slight or a marked decline in full scale IQ 1-5 years later. Angeard et al. [24] analysed intra-scalar IQ scores, within groups divided according to inheritance transmission. Subjects with maternal inheritance had the best scores in VIQ. However, most subjects had scores inferior to 1SD compared with age-paired norms (mean intra-scalar subscores ranging from 3.85 to 5.85). Subjects with paternal transmission had normal VIQ, although average intra-scalar subscores fell in the borderline zone (between 7.8 and 8.53). Patients presented their lowest PIQ scores in the object assembly (mean $=2.85$ and 6.67 for maternal and paternal transmission, respectively) and block design tasks (2.6 and 3.93, for maternal and paternal transmission, respectively). These subtests had a strong inter-subtest correlation, indicating a probable visual spatial deficit.

\section{Developmental delay and learning disabilities}

Although not evaluated in clinical series, several case descriptions reported that children with DM1 sometimes exhibited early motor development delay (sitting without support after 8 months, walking alone after 18 months), hypotonia and motor coordination impairments [16, 20, 21, 23]. Others showed speech and language delay [18, 19]. Echenne et al. [25] found that $73.3 \%$ (11/15) of DM1 patients investigated had speech or language delay as an isolated manifestation until adolescence. However, learning disabilities were the most prominent symptoms reported in juvenile DM1. School difficulties were particularly common with $69-86.7 \%$ of patients being academically delayed [10, 23, 25]. Goosens et al. [23] reported that of the 21 patients who attended school, only 4 subjects were in a normal school programme, whereas $17(81 \%)$ subjects were in a special education programme (11 for children with mild mental retardation, 3 for children with learning disabilities, 2 for motor disabled people and 1 for children with moderate mental retardation). One subject worked in a sheltered workshop.

Cohen et al. [10] investigated reading and spelling difficulties. Phonology, word identification efficacy score and speed were all significantly lower in the subjects with low verbal IQ $(<76)$, than in regular French school students, except for phonological sensitivity. As expected, subjects with DM1 were all below their expected literacy levels for reading tasks. In contrast, subjects with high verbal IQ did not exhibit lower scores for either phonology or word identification. However, they had difficulties in global reading tasks and reading impairments were frequent. Most of the patients had scores superior to the level of literacy for age-matched subjects French people in the short prose text task, but $55 \%$ of the patients exhibited difficulties with the long prose text task, although this task was linguistically more simple. Sixty-six percent of the subjects with normal IQ had difficulties extracting proper information in a TV schedule task. Finally, $82 \%$ had moderate to severe difficulties in spelling tasks. The severity of these learning difficulties correlated with longer mutation length and with maternal transmission, but could not be related to phonological deficit. Furthermore, 16 (69\%) subjects had or were undergoing reading therapy, and some of these subjects were in the high-cognitive group (63.6\%).

\section{Psychiatric disorders}

Four studies systematically reported psychiatric impairments, but only two used standardised instruments. Using the CBCL parent form, Steyaert et al. and Goosens et al. showed that $28.57 \%$ (Steyaert) to $42 \%$ (Goosens) of the subjects' scores were in the clinical range for total problems. Nearly $40 \%$ of the patients in both studies had internalising problems, whereas $6-8 \%$ scored in the clinical range of the externalising subscale. On the separate symptoms clusters, three main dimension mean scores were found in the clinical range: "withdraw", "social problem" and "attention problem", with reported frequency of pathological scores of 29,54 and $37 \%$, respectively [23]. No correlation between the IQ and CBCL total problem score could be demonstrated. Similarly, no correlation was found between CTG repeat mutation length and CBCL total problem score.

Regarding psychiatric diagnosis, in the two studies that used a structured interview, the majority of the patients had an axis 1 DSM diagnosis $(56.25 \%$ in Steyaert et al. and $63 \%$ in Goosens et al.). Attention deficit with hyperactivity disorder (ADHD) was the most frequent diagnosis reported, with an average rate of $30 \%$ in both studies; significantly higher than in the general population [24]. Goosens [23] noticed that the inattentive subtype was the most frequent. In Echenne's study [25], where a standardised 
Fig. 2 Admixture analysis of the observed distribution of IQ scores in 36 patients with juvenile myotonic dystrophy. The likelihood ratio test indicated that the model with two distributions fit the observed distribution of IQ significantly better than the model with one distribution $\left(\chi^{2}=9.45, d f=3, P=0.024\right)$. No further improvement was obtained with a three component model. The mean IQ scores estimated in this model were $58( \pm 9)$ and $91( \pm 13)$

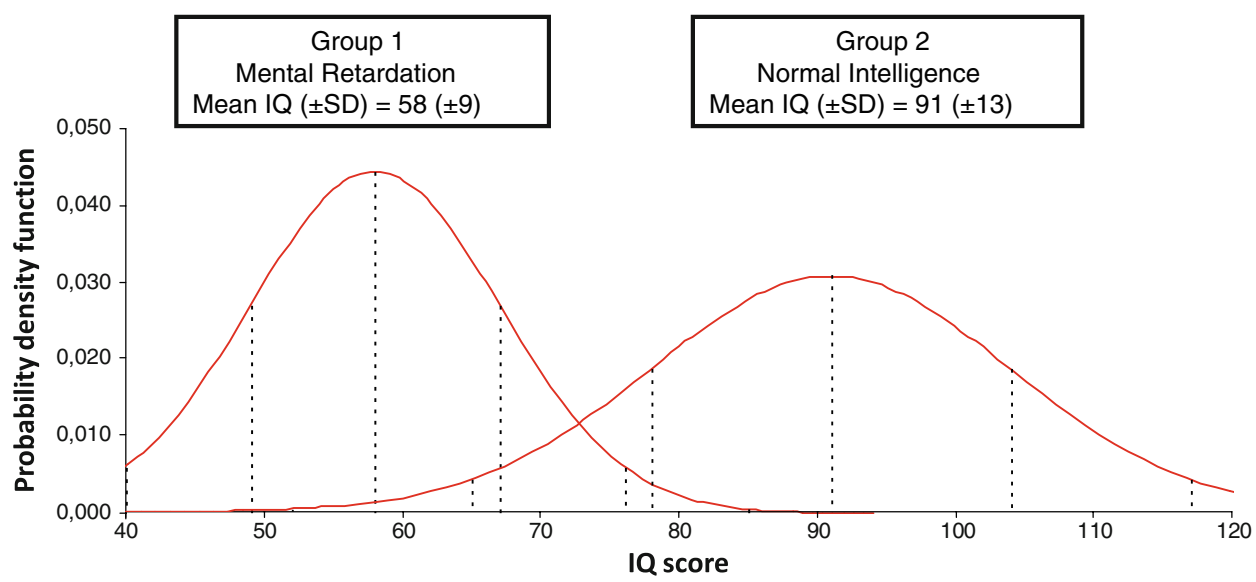

instrument was not used, ADHD was found in $26 \%$ of the patients but was not the most frequent diagnosis. Conduct disorder was reported in $40 \%$ of the patients, but these results contrasted with the more detailed descriptions of these children found in case reports, where they were described as apathetic and quiet [11, 12, 14]. In Ekstrom's study [27], only $11 \%$ of patients had ADHD, whereas $16.7 \%$ of patients $(3 / 18)$ had an autistic disorder. In this series, which also included both severe $(N=19)$ and mild ( $N=18$ ) congenital forms of DM1, it was reported that the more severe the type of DM1, the higher the frequency of autism. As noted by the authors, none of the individuals exhibited self-injurious behaviours, and problems in the area of restricted, repetitive and stereotyped patterns of behaviour were very limited. In addition, three cases of Asperger syndrome were also reported [20, 21, 23]. The second most frequent diagnosis was anxiety disorder, diagnosed in $18.75 \%$ of patients in Steyaert et al. and $25 \%$ in Goosens et al. [22, 23]. Different types of anxiety were observed: generalised anxiety, separation anxiety and specific phobia. Other diagnoses were noticed in lower proportions: maladjustment disorder with depressive mood, enuresis disorder and encopresis disorder.

Finally, the study of Quera Salva et al. [26] found an important prevalence of sleep disorders in DM1 patients. Seventy six percent of children reported fatigue and $52 \%$ reported somnolence. Polysomnography evidenced that sleep was disturbed by numerous micro arousals caused by abnormal respiratory events in $26.8 \%$ of the children. Furthermore, $38 \%$ presented periodic limb movements, and $29 \%$ suffered from a sleep apnoea syndrome.

\section{Admixture analysis of IQ distribution}

To clarify whether two distinguishing subgroups could be established, we did an admixture analysis of the distribution of the IQ scores of the 36 patients of Angeard's series (see main characteristics of the study in Tables 1, 2). Our analysis confirmed that patients could be divided into two groups. We found two normal distributions of IQ scores (Fig. 2). The mean IQ scores estimated in this model were $58(\mathrm{SD}=9)$ and $91(\mathrm{SD}=13)$, dividing patients into two groups: one with normal intelligence and one with mild mental retardation. The likelihood ratio test indicated that the model with two distributions fit the observed distribution of IQ significantly better than the model with one distribution $\left(\chi^{2}=9.45, d f=3\right.$, $P=0.024)$. No further improvement was obtained with a three component model.

\section{Discussion}

Myotonic dystrophy type 1 is the most frequent inherited neuromuscular disease. The juvenile form is characterised by the rarity or the absence of the classical neurological or motor symptoms and by the presence of cognitive or psychiatric symptoms; often the first signs of the disease, which lead parents to consult with a specialist in a child psychiatric setting. Reviewing the literature showed that few systematic studies have been conducted on this aspect of the disease despite the importance of the cognitive and psychiatric symptoms and their impact on children's lives, as $69-86.7 \%$ of patients were academically delayed. In evaluating the review, one should consider its main limitations: (1) lack of standardised instruments to evaluate psychiatric diagnosis in most studies; (2) a tendency to include more severe patients in clinical series, resulting in more maternal transmission cases than paternal ones (Table 1); (3) the lack of a standardised cognitive evaluation across series, except for the Wechsler intelligence scale; and (4) the small sample size in most series.

The learning disabilities observed in DM1 patients could be explained by at least two factors. First, patients with 
juvenile DM1 may have mental retardation or borderline IQ. All studies found a significant effect on the length of the CTG repeat on cognitive abilities, with a negative correlation between the length of the CTG repeat expansion and IQ scores (full scale, verbal and performance subscales). A link between the transmission modes, with maternal transmission creating a negative effect on IQ, was also found. Although inheritance from the mother gave systematically longer repeat lengths, the question of an independent effect of the transmitting parent's sex on IQ still remains unclear. Second, even in patients with subnormal intelligence, some deficits were found in subtests of the cognitive assessment: attention was frequently described as impaired, but visual spatial and/or visual constructive skills and verbal working memory could also be disturbed. The attention deficit was diagnosed as a symptom of the ADHD syndrome in $1 / 3$ of the children. The hypothesis of a specific cognitive impairment in DM1 children was reinforced by the results of the study on learning disabilities by Cohen et al. [10]. This study found that DM1 children and adolescents had impaired written language skills, even in the absence of mental retardation; in particular, they had spelling and reading impairments, despite normal word identification. The severity of these learning difficulties was correlated with longer mutation length and maternal transmission, but could not be related to a phonological deficit, which distinguished these children from children with classical dyslexia. These difficulties are probably increased by the oral motor dysfunction and the impaired facial expression, as noticed in Sjögreen's study [32], but are also likely secondary to a visual spatial deficit and/or a motor coordination disorder.

The results of the cognitive assessment of juvenile DM1 patients are consistent with those found in patients with the adult form of DM1. These adult patients showed impairment in executive functions, attention deficit, abnormalities in visual perception, constructional ability and visual memory, following years of development of the disease; and this was irrespective of their IQ score [33-36]. Adults with DM1 also show mental retardation, but in a smaller proportion of 10-25\% [37]. Furthermore, IQ declines as the age of DM1 onset decreases and the CTG expansions increases [36, 38, 39]; although, IQ apparently does not correlate with the neuromuscular impairment. The cognitive defects are supported by neuropathological findings and neuroimaging: (1) reduced cerebral perfusion in the frontal and temporal lobes by $\mathrm{H}_{2} \mathrm{O}$ PET scan correlated with cognitive impairment [40]; (2) a variety of abnormalities were discovered such as neurofibrillary tangles, intracytoplasmic inclusions and subcortical white matter lesions with a breakdown of myelin sheets, with relative preservation of axons and the presence of fatty granular cells [41-43]. No imaging study is currently available in patients with the juvenile form of DM1. Finally, to our knowledge, the association of advanced parental age with low IQ in offspring [44] has never been tested in DM1 patients.

Our admixture analysis clarified significantly the hypothesis of a cognitive impairment in the juvenile form of DM1. Indeed, the analysis of IQ scores found a bimodal distribution. Patients' phenotypes were divided into two groups: one group with mental retardation (IQ mean $=58$ ), with an overrepresentation of subjects whose mothers were affected and one group without mental retardation, but with borderline full scale IQ (IQ mean = 91) and more paternal transmissions. In this latter group, VIQ is usually superior to PIQ, due to a visual spatial deficit. Therefore, according to the severity of the cognitive impairment, we propose to distinguish two phenotypes in the juvenile form of DM1 (Table 3). The first group (with mental retardation) is characterised by language and/or motor delay in infancy, severe learning disabilities, possible vigilance impairments including somnolence and maternal transmission. The second group (with borderline full scale IQ) has subnormal development, moderate learning disabilities, attention and visual spatial deficits and more cases of paternal transmission.

The study of psychiatric diagnoses of DM1 patients showed that two-thirds of the children met criteria for at least 1 axis 1 diagnosis: $1 / 3$ of the children suffered from ADHD and 1/4 of the children presented anxiety disorders. Anxiety disorders were associated with other internalising symptoms, such as withdrawal, phobia and social

Table 3 Distinguishing two phenotypes in the juvenile form of DM1 according to severity

\begin{tabular}{cll}
\hline & Severe & Mild \\
\hline IQ & $\begin{array}{c}\text { Mild mental } \\
\text { retardation }\end{array}$ & $\begin{array}{l}\text { Normal/borderline } \\
\text { Verbal } \\
\text { IQ }>\text { Performance IQ }\end{array}$ \\
& & Subnormal \\
Development and & Hypotonia & Motor coordination \\
early signs & Motor delay & disorder \\
& Speech and language & \\
& delay & Learning disabilities \\
Other cognitive & Learning disabilities & Visual spatial deficit \\
dysfunctions & Visual spatial deficit & ADHD \\
Psychiatric signs & ADHD & ADH \\
& Somnolence & Attention deficit \\
& Anxiety and & Anxiety and depression \\
depression & \\
Differential & Pervasive & Social phobia \\
diagnosis & developmental & Specific learning/ \\
& disorders & developmental disorder \\
Transmission & Maternal & Paternal \\
\hline
\end{tabular}


interaction problems. In the adult form of DM1, patients frequently exhibit (about 20\%) an avoidant personality disorder, characterised by social inhibition, anxiety and a high sensitivity to criticism [45-47]. The question of a link between withdrawal and anxiety disorders in childhood and the development of a personality disorder in adulthood should be explored. These anxious manifestations may be a consequence of two different phenomena: first, as a secondary and nonspecific sign due to the child's difficulty in living with a severe, chronic and handicapping disease, but also, secondly, as a possible consequence of motor coordination disorder and visual spatial impairment. A link between anxiety development and withdrawal style was supported by studies in children with motor coordination disorder, regardless of the cause [48]. It would, then, be interesting to systematically assess the occurrence of motor coordination disorder or visual spatial deficit in children with DM1. Regarding the withdrawal symptoms, they could be interpreted as a sign of social interaction difficulty belonging to the autism spectrum. Two papers reported cases of Asperger syndrome, and Ekström et al. found that $16.7 \%$ of patients with the juvenile form of DM1 had an autistic disorder [27]. Furthermore, a deficit in facial emotion recognition has also been described in adults with DM1 [47]. However, we consider pervasive developmental disorder as a differential diagnosis for DM1 (Case 1): (1) Ekström et al. found a correlation between the occurrence of autism/mental retardation and the severity of DM1; (2) interpretation by parents of early social skills is difficult due to affected infants' hypotonia and amimic faces; (3) speech and language delay is frequent, and a high score in this dimension may not be specific; (4) no subject with autism spectrum conditions $(N=28)$ in the Ekström study had self-injurious behaviour. However, it may be possible that DM1 offers a model, illustrating a continuum along forms of DM1, for autistic disorders and severe social anxiety. In the field of genetic disease, this is the case for fragile $\mathrm{X}$ syndrome, with autism being associated with affected males and social anxiety with affected females [49].

The occurrence of ADHD, found in four studies to be $16-33 \%$, with a majority of the inattentive subtype, raises many questions. First, is there a link between attention impairment and sleep/vigilance disorder? In fact, 38\% of children with juvenile DM1 present periodic limb movements and 29\% have sleep apnoea syndrome [26]. The association between ADHD and sleep disorder was described in ADHD children, for whom sleep apnoea disorders and non-restless limb movements were described [50]. Alternatively, sleep/vigilance disorders were also observed in the adult form of DM1 after years of development [51-53]. Second, is the diagnosis of ADHD valid in DM1 children given the link between attention deficit, vigilance problems and sleep disorders? ADHD could be interpreted as a misdiagnosed form of a vigilance problem. Conversely, vigilance problems could be a form of severe attention deficit, or finally, we could also hypothesise that both disorders share common underlying mechanisms. This association suggests important therapeutic possibilities for psycho-stimulant drugs.

Regarding the therapeutic approach and research perspectives, we consider that children with juvenile DM1 deserve more specific research on treatments. First, stimulant medication should be investigated for treating attention deficit and/or vigilance impairment. However, DM1 is a poly-system disease including cardiac risk and this risk needs to be specifically explored and monitored. Several cases of cardiac arrhythmias, some resulting in sudden death, have been reported [54] in young patients with juvenile DM1. Therefore, amphetamines should be avoided; either atomoxetine or modafinil is preferred. Atomoxetine is a first-line agent in the treatment of ADHD for both the American Academy of Child and Adolescent Psychiatry [55] and the European Clinical Guidelines [56]. A recent pooled analysis of two long-term extension studies following 16 short term trials and including 714 patients treated with atomoxetine for more than 3 years showed reassuring data regarding cardiac tolerability and safety [57]. Modafinil is not a first-line agent yet, but was recently evaluated in a double-blind placebo controlled trial in children with ADHD [58] and also in an open trial for adults with DM1 who suffered from fatigue or somnolence [59]. Second, given the prevalence of learning difficulties, language remediation and reading therapy should be addressed as well. There is also a requirement for further research in assessing the visual spatial deficits and motor coordination disorder of children with juvenile DM1.

In summary, the results presented herein suggest many questions about the specificity of the observed symptoms, as illustrated by two clinical studies. Case 1 shows the importance of the cognitive impairment as well as the possible secondary consequences of visual spatial difficulties and motor coordination impairments on social interaction. In addition, there is a probable deficit in facial emotion recognition as described in adults [41]. The second case report describes the presence of symptoms clearly secondary to the disease (learning disabilities and borderline efficiency), but also symptoms secondary to the maladjustment to the disease during adolescence (mythomanic inventions and depressive symptoms). 


\section{Case reports}

Case report 1
Patient 1 was a 4-year-old boy with a history of language delay, phobias and difficulty in social
interactions with peers. The primary care medical team suspected a pervasive developmental disorder
(PDD). By 2 years, the boy was receiving occupational therapy and speech therapy twice a week. He
exhibited no visual contact, peripheral gaze, no affective expression, facial atonia and global
developmental delay. He was described as awkward and clumsy, often banging into things, with no
consciousness of space. Despite the dramatic improvements in social contact and language, he was
referred for a complete evaluation when he was 4 years. PDD was eliminated, as he looked like a very
shy child; passive but accepting of contact with adults, seeking relations with peers with maladaptive
physical contact. We confirmed developmental delay, motor coordination disorder and hypotonia. The
language evaluation revealed an important language delay, phonological impairment, a challenging
fatigability, attention deficit and myotonia of the tongue. The intellectual quotient assessment was in
the range of mild mental retardation (IQ $=58$, VIQ $=63$, PIQ $=63)$. A neuropediatric evaluation
suspected DM1. The genetic assessment confirmed the diagnosis, with a number of CTG repeats around
800 . The diagnosis made on patient 1 steered us to diagnose his mother, who was also carrying the
mutation on the DMPK gene. To date, she showed a mild myotonic syndrome and no complaints.

\footnotetext{
Case report 2

Patient 2 was a 17-year-old girl, referred to the child and adolescent psychiatric department for a diagnosis evaluation. She was born at term after a normal pregnancy, labour and delivery. Her development was normal. She was described in childhood as awkward and isolated, with poor social contact with peers. Her integration with other children was described as difficult because of her clumsiness and the consequent impossibility of partaking in play with her peers. She had early learning disabilities and stopped school at the age of 14 in a context of oppositional behaviours with peers. At adolescence, opposition extended to her parents, particularly to her mother. DM1 disease was present in her mother, who had the classical form (cataract, myotonia and fatigue), but also in her grandfather and three uncles and aunts, who had a mild form (cataracts and no neurological symptoms). During admission, she presented a delusion where she described herself as the daughter of Céline Dion. She had no negative symptoms, dissociative symptoms or hallucinations. The symptoms regressed spontaneously when she was hospitalised without medication and separated from the family. Her symptoms included mythomaniac inventions in the context of a known heritable disease, a family conflict and borderline intellectual efficiency $(I Q=69)$. A complementary cognitive evaluation showed executive dysfunctions and language deficit, explaining the severity of her learning disabilities. Projective (Rorschach and TAT) testing showed mythomanic defences against depressive feelings and fear of death. Family therapy was recommended, and she was referred to a special education programme.
}

\section{Conclusion}

Children with juvenile DM1 present a specific cognitive and psychiatric profile characterised by attention deficit, social anxiety, learning disabilities, visual spatial impairments and motor coordination disorder. Two different subtypes of juvenile DM1 can be distinguished, based on CTG expansions and the transmitting parent: one group characterised by mental retardation, severe developmental delay and maternal transmission and a second group characterised by borderline full scale IQ, subnormal development and paternal transmission. Juvenile DM1 requires further research on therapeutic perspectives while considering these various clinical aspects of the phenotype.

Acknowledgments This work was supported by the Association Française contre les Myopathies (AFM no 11,839). The authors wish to thank the CARPIJ for the support they provide to research in child and adolescent psychiatry.

Conflict of interest statement The authors have no conflicts of interest relevant to the manuscript. 


\section{References}

1. Hunter A, Tsilfidis C, Mettler G, Jacob P, Mahadevan M, Surh L, Korneluk R (1992) The correlation of age of onset with CTG trinucleotide repeat amplification in myotonic dystrophy. $\mathrm{J}$ Med Genet 29:774-779

2. Darin N, Tulinius M (2000) Neuromuscular disorders in childhood: a descriptive epidemiological study from western Sweden. Neuromuscul Disord 10:1-9

3. Aslandis C et al (1992) Cloning of the essential myotonic dystrophy region: mapping of the putative defect. Nature 335:548551

4. Brook JD et al (1992) Molecular basis of myotonic dystrophy: expansion of a trinucleotide (CTG) repeat at the $3^{\prime}$ end of a transcript encoding a protein kinase family member. Cell 68:799808

5. Bruxton J et al (1992) Detection of an unstable fragment of DNA specific to individuals with myotonic dystrophy. Nature 355:547548

6. Harley HG, Rundle SA, MacMillan JC, Myring J, Brook JD, Crow S, Reardon W, Fenton I, Shaw DJ, Harper PS (1993) Size of the unstable CTG repeat sequence in relation to phenotype and parental transmission in myotonic dystrophy. Am J Hum Genet 52(6):1164-1174

7. Harper PS (1989) Myotonic dystrophy, 2nd edn. WB Saunders, Philadelphia

8. Ashizawa T, Anvret M, Baiget M, Barcelo JM, Brunner H, Cobo $\mathrm{AM}$ et al (1994) Characteristics of intergenerational contractions of the CTG repeat in myotonic dystrophy. Am J Hum Genet 54(3):414-423

9. Moorman JR, Coleman RE, Packer DL, Kisslo JA, Bell J, Hettleman BD, Stajich J, Roses AD (1985) Cardiac involvement in myotonic muscular dystrophy. Medicine 64:371-387

10. Cohen D, Plaza M, Angeard N, Lanthier-Gazzano O, Baraud P, Rivière JP et al (2006) Reading and spelling impairments in children and adolescents with infantile myotonic dystrophy. J Neurolinguistic 19(6):455-465

11. Vanier TM (1960) Dystrophia myotonica in childhood. Br Med J 2(5208):1284-1288

12. Dodge PR, Gamstorp I, Byers RK, Russel P (1965) Myotonic dystrophy in infancy and childhood. Pediatrics 35:3-19

13. Giraud P, Orsini A, Soulayrol R, Cl Raybaud (1963) A case of Steinert's disease in the second stage of childhood. Pédiatrie 18:218-221

14. Verger P, Guillard JM, Eschapasse P (1967) Steinert's disease (myotonic myopathy) in early childhood. Ann Pediatr 14(11):745-749

15. Dubowitz V (1972) Dystrophia myotonica in infancy and childhood. Arch Dis Child 47(254):671-672

16. Turpin JC, Morice J (1980) La gravité de la dystrophie myotonique de Steinert. Sem Hôp 56(7-8):335-340

17. Lanzi G, Besana D, Ottolini A, Venco A (1982) Myotonic dystrophy in childhood. Acta Neurol Belg 82:150-158

18. Novelli G, Gennarelli M, Menegazzo E, Angelini C, Dallapiccola B (1985) Discordant clinical outcome in myotonic dystrophy relatives showing $(\mathrm{CTG}) \mathrm{n}>700$ repeats. Neuromuscul Disord 5:157-159

19. de Die Smulders CE, Höweler CJ, Mirandolle JF, Brunner HG, Hovers V, Brüggenwirth H, Smeets HJ, Geraedts JP (1994) Anticipation resulting in elimination of the myotonic dystrophy gene: a follow up study of one extended family. J Med Genet 31(8):595-601

20. Blondis TA, Cook E, Koza-Taylor P, Finn T (1996) Asperger syndrome associated with Steinert's myotonic dystrophy. Dev Med Child Neurol 38:840-847
21. Blondis TA (1997) Asperger syndrome associated with Steinert's myotonic dystrophy. Dev Med Child Neurol 39:280-281

22. Steyaert J, Umans S, Willekens D, Legius E, Pijkis E, De Die-Smulders C et al. (1997) A study of the cognitive and psychological profile in 16 children with congenital or juvenile myotonic dystrophy. Clin Genet 52(3):135-141

23. Goossens E, Steyaert J, De Die-Smulders C, Willekens D, Fryns JP (2000) Emotional and behavioural profile and child psychiatric diagnosis in the childhood type of myotonic dystrophy. Genet Couns 11:317-327

24. Angeard N, Gargiulo M, Jacquette A, Radvanyio H, Eymard B, Héron D (2007) Cognitive profile in childhood myotonic dystrophy type I: is there a global impairment? Neuromuscul Disord 17(6):451-458

25. Echenne B, Rideau A, Roubertie A, Sébire G, Rivier F, Lemieux B (2008) Myotonic dystrophy type I in childhood: long-term evolution in patients surviving the neonatal period. Eur J Paediatr Neurol 12(3):210-223

26. Quera Salva MA, Blumen M, Jacquette A, Durand MC, Andre S, De Villiers M, Eymard B, Lofaso F, Heron D (2006) Sleep disorders in childhood-onset myotonic dystrophy type 1 . Neuromuscul Disord 16(9-10):564-570

27. Ekström AB, Hakenäs-Plate L, Samuelsson L, Tulinius M, Wentz E (2008) Autism spectrum conditions in myotonic dystrophy type 1: a study on 57 individuals with congenital and childhood forms. Am J Med Genet Part B 147B(6):918-926

28. Cohen D, Martel C, Wilson A, Déchambre N, Amy C, Duverger L, Jm Guile, Piripas E, Benzacken B, Cavé H, Cohen L, Héron D, Plaza M (2007) Visual-spatial deficit in a 16-year-old girl with maternally derived duplication of proximal 15q. J Autism Dev Disord 37:1585-1592

29. Winterkorn EB, Pulsifer MB, Thiele EA (2007) Cognitive prognosis of patients with tuberous sclerosis complex. Neurology 68:62-64

30. Bellivier F, Golmard JL, Rietschel M, Schulze TG, Malafosse A, Preisig M, McKeon P, Mynett-Johnson L, Henry C, Leboyer M (2003) Age at onset in bipolar I affective disorder: further evidence for three subgroups. Am J Psychiatry 160:999-1001

31. Consoli A, Soultanian C, Tanguy ML, Laurent C, Perisse D, Luque R, Berrios G, Cohen D (2007) Cotard's syndrome in adolescents and young adults is associated with an increased risk of bipolar disorder. Bipolar Disord 9:665-668

32. Sjögreen L, Engvall M, Ekström AB, Lohmander A, Kiliaridis S, Tulinius M (2007) Orofacial dysfunction in children and adolescents with myotonic dystrophy. Dev Med Child Neurol 49:18-22

33. Angeard-Durand N, Héron D, Gargiulo M, Eymard B (2004) Dystrophie myotonique de Steinert: approche génétique et cognitive. Neuropsychiatr Enf 52:175-180

34. Winblad S, Lindberg C, Hansen S (2006) Cognitive deficits and CTG repeat expansion size in classical myotonic dystrophy type 1 (DM1). Behav Brain Funct 15:2-16

35. Sansone V, Gandossini S, Cotelli M, Calabria M, Zanetti O, Meola G (2007) Cognitive impairment in adult myotonic dystrophies: a longitudinal study. Neurol Sci 28:9-15

36. Van Spaendonck KP, Ter Bruggen JP, Weyn Banningh EW, Maassen BA, Van de Biezenbos JB, Gabreëls FJ (1995) Cognitive function in early adult and adult onset myotonic dystrophy. Acta Neurol Scand 91:456-461

37. Black FW (1973) Intellectual ability as related to age and stage of disease in muscular dystrophy: a brief note. J Psychol 84:333-334

38. Turnpenny P, Clark C, Kelly K (1994) Intelligence quotient profile in myotonic dystrophy, intergenerational deficit, and correlation with CTG amplification. J Med Genet 31:300-305 
39. Modoni A, Silvestri G, Pomponi MG, Mangiola F, Tonali PA et al (2004) Characterization of the pattern of cognitive impairment in myotonic dystrophy type 1. Arch Neurol 61:1943-1947

40. Meola G, Sansone V, Perani D, Colleluori A, Cappa S, Cotelli M, Fazio F, Thornton CA, Moxley RT (1999) Reduced cerebral blood flow and impaired visual-spatial function in proximal myotonic myopathy. Neurology 53:1042-1050

41. Di Costanzo A, Di Salle F, Santoro L, Bonavita V, Tedeschi G (2002) Brain MRI features of congenital- and adult-form myotonic dystrophy type 1: case-control study. Neuromuscul Disord $12: 476-483$

42. Di Costanzo A, Di Salle F, Santoro L, Bonavita V, Tedeschi G (2001) Dilated Virchow-Robin spaces in myotonic dystrophy: frequency, extent and significance. Eur Neurol 46:131-139

43. Endo A, Motonaga K, Arahata K, Harada K, Yamada T, Takashima S (2000) Developmental expression of myotonic dystrophy protein kinase in brain and its relevance to clinical phenotype. Acta Neuropathol 100:513-520

44. Malaspina D, Reichenberg A, Weiser M, Fennig S, Davidson M, Harlap S, Wolitzky R, Rabinowitz J, Susser E, Knobler HY (2005) Paternal age and intelligence: implications for age-related genomic changes in male germ cells. Psychiatr Genet 15(2):117125

45. Meola G, Sansone V, Perani D, Scarone S, Cappa S et al (2003) Executive dysfunction and avoidant personality trait in myotonic dystrophy type 1 (DM1) and in proximal myotonic myopathy (PROMM/DM2). Neuromuscular Disord 13:813-821

46. Delaporte C (1998) Personality patterns in patients with myotonic dystrophy. Arch Neurol 55:635-640

47. Winblad S, Lindberg C, Hansen S (2005) Temperament and character in patients with classical myotonic dystrophy type 1 (DM-1). Neuromuscul Disord 15:287-292

48. Xavier J, Mayer C, Kloechner A, Perisse D, Plaza M, Cohen D (2006) Les dyspraxies de l'enfant: le point de vue du psychiatre. ANAE 18:226-233

49. Cohen D, Pichard N, Tordjman S, Baumann C, Burglen L, Excoffier S, Lazar G, Mazet Ph, Pinquier C, Verloes A, Heron D
(2005) Specific genetic disorders and autism: clinical contribution towards identification. J Autism Dev Disord 35:103-116

50. Cortese S, Konofal E, Yateman N, Mouren MC, Lecendreux M (2006) Sleep and alertness in children with attention-deficit/ hyperactivity disorder: a systematic review of the literature. Sleep 29:504-511

51. Rubinsztein JS, Rubinsztein DC, Goodburn S, Holland AJ (1998) Apathy and hypersomnia are common features of myotonic dystrophy. J Neurol Neurosurg Psychiatry 64:510-515

52. Broughton R, Stuss D, Kates M, Roberts J, Dunham W (1990) Neuropsychological deficits and sleep in myotonic dystrophy. Can J Neurol Sci 17:410-415

53. Gibbs JWIII, Ciafaloni E, Radtke RA (2002) Excessive daytime somnolence and increased rapid eye movement pressure in myotonic dystrophy. Sleep 25:662-665

54. Bassez G, Lazarus A, Desguerre I, Varin J, Laforêt P, Bécane HM, Meune C, Arne-Bes MC, Ounnoughene Z, Radvanyi H, Eymard B, Duboc D (2004) Severe cardiac arrhythmias in young patients. Neurology 63:1939-1941

55. AACAP Official Action (2007) Practice parameter for the assessment and treatment of children and adolescents with attention deficit/hyperactivity disorder. J Am Acad Child Adolesc Psychiatry 46(7):894-921

56. (2004) European Clinical Guideline for hyperkinetic disorderfirst upgrade. Eur Child Adolesc Psychiatry 13(Suppl 1):1/7-1/30

57. Donnely C et al (2009) Safety and tolerability of atomoxetine over 3 to 4 years in children and adolescents with ADHD. J Am Acad Child Adolesc Psychiatry (in press)

58. Greenhill LL, Biederman J, Boellner SW, Rugino TA, Sangal RB, Earl CQ et al (2006) A randomized double-Blind, placebocontrolled study of modafinil film coated tablets in children and adolescents with attention-deficit/hyperactivity disorder. J Am Acad Child Adolesc Psychiatry 45:503-511

59. Mc Donald JR, Hill JD, Tarnopolsky MA (2002) Modafinil reduces excessive somnolence and enhances mood in patients with myotonic dystrophy. Neurology 59:1876-1880 